Research Article

\title{
The Integration of Blockchain Technology and Smart Grid: Framework and Application
}

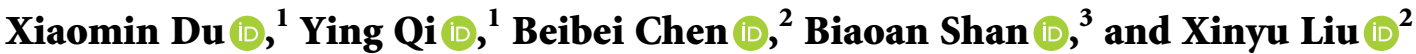 \\ ${ }^{1}$ Department of Economic Management, Yingkou Institute of Technology, Yingkou 115014, China \\ ${ }^{2}$ School of Economics and Management, Dalian University of Technology, Dalian 116024, China \\ ${ }^{3}$ School of Management, Jilin University, Changchun 130022, China \\ Correspondence should be addressed to Biaoan Shan; shanbiaoan@jlu.edu.cn
}

Received 28 March 2021; Revised 20 April 2021; Accepted 6 May 2021; Published 17 May 2021

Academic Editor: Ming Bao Cheng

Copyright ( $\odot 2021$ Xiaomin Du et al. This is an open access article distributed under the Creative Commons Attribution License, which permits unrestricted use, distribution, and reproduction in any medium, provided the original work is properly cited.

Based on the diffusion of blockchain technology in the smart grid, this paper studies the framework and application of the blockchain technology in the smart grid, so as to combine the blockchain with the smart grid and establish a sustainable supply chain. However, the establishment of a sustainable supply chain is based on a layered theoretical framework. Not only should the framework take into account needless attributes and the relationship among various criteria and aspects but the application should also involve a balance of multiple stakeholders. For the above reasons, this paper uses a combination of Fuzzy-DEMATEL and ISM. The results show that (1) the hierarchical path of sustainable supply chain management of the smart grid under the blockchain starts from the social level, pays attention to system construction, grasps the technical standards, and defines the development goals of the power grid. (2) The development of green energy has become a new market growth point. (3) The control of the operation level becomes the focus of the smart grid. (4) The optimization and development of the economic structure are restricted by social factors. By integrating and optimizing the blockchain and supply chain, this paper puts forward a theoretical framework, establishes a sustainable GIP application system with multistakeholder participation at the supply chain level, and indicates the significance of the blockchain in the smart grid.

\section{Introduction}

The smart grid is a transparent, seamless, and instant twoway transmission of energy and information. The two-way information exchange between power grids and users is the biggest difference between smart grids and traditional power grids [1]. As another disruptive technological innovation occurring after the internet, blockchain has led to the development of distributed accounting system $[2,3]$, which is tamper-resistant, traceable, highly trusted, and decentralized. Blockchain can improve the security of the grid system data and help promote the realization of the reliable, effective, and trusted distributed smart grid system [4]. There have been many studies on blockchain in the energy field. In addition, blockchain technology may also subvert the supply chain [5]. This article combines the blockchain with a smart grid and establishes a grid alliance chain with the participation of governments, enterprises, and individuals. The grid alliance chain can perform data uploads, storage, and condition queries, which promotes the further development of smart grids.

Firstly, in the entire energy industry, the construction of power grids is at the forefront of development, and the development of smart grids under the blockchain has become a focus of scholars' attention. Some scholars have explored the development of the smart grid industry under the blockchain, but this research is still in the preliminary stage and lacks systematization. Most studies on the combination of the blockchain and smart grids focus on the application of blockchain technology in a single part of the grid value chain, such as the construction of smart grid data secure storage and sharing systems based on an alliance's blockchain [6], blockchain-based distributed secure keyless signature schemes [7], distribution networks and point-to- 
point energy trading platforms [8], and energy demand-side management in microgrids under blockchain technology [9]. It is not difficult to find that the development systems of smart grids under the blockchain are highly complex, but the existing research is scattered and lacks integration. Secondly, the smart grid supply chain is a system composed of organization, personnel, information, and resources [10]. Supply chains are complex by nature, and inefficient supply chains can lead to a more serious crisis of trust, thus requiring better information sharing and verifiability [5]. The blockchain will work with all the agents of smart grids at the same time in the process of application, and multiple agents will work together and affect each other. However, from the perspective of stakeholder, scholars have performed little research on the multisubject coordinated development of systems. From the perspective of sustainability, there is little research on the integration of the blockchain and smart grid, which needs to be considered from three aspects: economy, society, and environment. Thirdly, the application space of private chains is limited because it easily leads to questioning the credibility of information. In contrast to private chains, public chains have greatly improved information credibility, but they cannot ensure the privacy and security of participants $[11,12]$. The aforementioned problems have increased the difficulty of the application and popularization of public chains in the real economy. Relatively speaking, alliance chains have the characteristics of "partial decentralization." As long as a limited number of subjects are included, an alliance chain can increase security, reduce costs, and increase reliability.

Therefore, this paper has conducted the following research. Firstly, the paper systematically discusses how blockchain technology affects the development of the smart grid supply chain. Sustainability is defined by the concept of triple bottom line [5]. The paper establishes a set of sustainable development system of blockchain-based smart grids including 14 standards from three aspects. Secondly, this study analyzes the causality and sorts out the interrelationships among different levels, building an influence path of the blockchain on the smart grid sustainable development. Thirdly, we construct a smart grid sustainable supply chain based on the blockchain from the three layers: government layer, information layer, and participant layer.

We finally reached these conclusions. (1) The impact is reflected in the three aspects. However, the importance of these three aspects is different. First, the development path of smart grids under the blockchain is based on solving social problems and reflects the characteristics of national security and people's dependence on the power industry. At the same time, transactions for renewable new energy are realized under the blockchain technology, which also shows that the blockchain has increased the trading space of new energy. (2) Control at the operation level has become the main point of smart grid construction under the blockchain, which is mainly carried out through smart contracts. In addition, the economic structure of a smart grid is restricted by social factors. The economic benefits generated by the realization of social benefits have become a potential core feature of the power grid industry. (3) The system should be built from three levels of government, information, and participant. This study elaborates the construction path of the sustainable supply chain of the smart grid under the blockchain and promotes the combination of blockchain and smart grid. In theory, this paper makes up the research gap of the lack of systematic application of the blockchain in the smart grid field. In practice, the government-led and multiparticipatory GIP application system of the power grid alliance chain designed in this paper will contribute to the future work of the smart grid and provide an important reference for government policy update and business planning.

The rest of the paper is structured as follows. Section 2 proposes 14 criteria through the literature review. Section 3 describes the calculation steps of the method in detail. Section 4 obtains the relationship diagram and hierarchical framework among criteria. Section 5 constructs a sustainable smart grid supply chain under the blockchain based on the results. Section 6 draws the conclusion.

\section{Literature Review}

The concept of a smart grid integrates many aspects. Dileep [1] described a smart grid as a transparent, seamless, and instant two-way transmission of energy and information. In contrast to traditional power grids, smart grids will expand the ability to obtain grid panorama information. Smart grids can strengthen the real-time analysis, diagnosis, and optimization of power grid business flows to achieve more refined, accurate, and timely power grid operation and management. Smart grid technology is bringing innovation to the power industry and affecting all parts of the grid supply chain [13]. A supply chain consists of a number of entities related to the product and service life cycle from both upstream and downstream markets, and blockchain technology can make supply chain management data sharing safe and transparent [14]. Smart grid technology creates new challenges in terms of security and intelligence [4]. Blockchain is open and transparent and involves decentralized database technology. Effectively applying blockchain technology to the construction of smart grids has attracted widespread attention from scholars. To solve the security and intelligence problems of smart grids, many scholars have proposed solutions based on blockchain technology. Gao et al. [15] used a sovereign blockchain to automatically record and control power consumption in a power grid. In addition, Mengelkamp et al. [16] and Pop et al. [17] proposed blockchain-based smart grid solutions. By using blockchain technology, smart grid supply chain can simultaneously achieve secure transaction data storage while also stimulating the use of green energy and promoting sustainable development [18].

This paper starts from the triple bottom line theory and focuses on economic, social, and environmental aspects. We consider the cost and efficiency of the public infrastructure in the economic aspect, social welfare and top-level design issues in the social aspect, and low carbon emission and green energy in the environmental aspect. 


\subsection{Economy}

2.1.1. Public Infrastructure Utilization Efficiency. Many scholars have used blockchain technology to solve infrastructure problems in the construction of smart grids. Blockchain technology will drive more distributed grid infrastructure and allow local producers to trade in the energy market. This will attract more resources that can invest in distributed grid technology [19]. The technical form of blockchain is highly compatible with the construction of the ubiquitous electric power [20].

2.1.2. Production Cost Management. It has been confirmed that smart grids under blockchain technology can reduce the production cost of power generation, effectively use the existing power infrastructure, and reduce carbon dioxide emissions [21]. Demand-side management under the blockchain can achieve supply and demand balance, achieve optimal production and power generation efficiency, and thus perform better in terms of production cost management [22].

2.1.3. Administration Cost Management. Smart contracts can reduce paper usage, facilitate quick discussions, and save time. At the same time, shared databases can reduce management work [23]. Blockchain can guarantee the security of the entire system through distributed accounting without having to go through a central agent or intermediary. Smart contracts stored in the blockchain can be automatically triggered in a decentralized manner, greatly saving management and service costs [24]. Blockchain technology helps smart grids use advanced power engineering and wireless communications to improve services and reduce administration costs [10].

2.1.4. Transaction Cost Management. Blockchain technology can eliminate information asymmetry by providing historical transaction records. The information cannot be changed retroactively, so the governance intermediary can be eliminated, and transaction costs can be reduced [25]. This process can lead to more short-term dynamic relationships and temporary partnerships, reducing the cost of renegotiating, drafting contracts and agreements, and implementing agreements [26]. Blockchain has features such as a decentralized database and encrypted signature protection, which can reduce the need for middlemen and transaction costs [27]. Smart contracts are usually used to realize automatic power trading and payment [14].

2.1.5. Financial Cost Management. According to the theory of information asymmetry, tax-related information is the starting point of tax collection and management. Incomplete information and information asymmetry in tax collection and management will lead to moral hazard and adverse selection, which will lead to tax loss [28]. Blockchain technology does not need to rely on any third-party transactions. Due to the characteristics of smart contracts, blockchain can automatically achieve pairing between two parties. These characteristics allow the blockchain to automatically provide complete and accurate historical transaction records and clearing processing. This can reduce the traditional disadvantages of information asymmetry, greatly simplify the taxation process, and promote a harmonious relationship between two parties [29]. Auditing cost control has always been a major concern of national auditing departments. Processing audit data through blockchain technology can effectively control auditing costs [30].

\subsection{Society}

2.2.1. Security. Key management is critical to improve the security of smart grids. Blockchain is a subversive innovation of key management of the smart grid system [7]. In a blockchain system, any operation on a given block will result in a hash mismatch of all contiguous blocks, and many new applications combine distributed ledger technology with smart contracts. It is almost impossible for a third party to tamper or review private information [23]. Each participating user in a blockchain system has its own public and private keys. An exclusive public key is issued to all network users who use the same encryption or decryption algorithm, while private keys are held by only the users themselves [24].

2.2.2. Authenticity. Blockchain guarantees the authenticity of transaction information in the operation of smart grid systems with traceability and transparency. The key feature of blockchain is its ability to maintain a consistent view and consensus among participants [31], even though some of them may not be honest [32]. Information recorded by the blockchain is backed up on multiple nodes. Information updates require the joint authentication of multiple nodes. One node cannot cheat the other nodes. Therefore, the authenticity of information is enhanced [33].

2.2.3. Timeliness. By introducing blockchain technology, certain security services used by power grid operators and user agreements can be implemented in the form of smart contracts, which can save process time, reduce mistakes and improper behaviors in the sales process, and improve the timeliness and reliability of services [21]. In addition, smart contracts enable companies to develop business at a lower cost while improving service efficiency [34]. Transactions between entities in a smart grid will be more efficient as security improves.

2.2.4. Credit Evaluation System. Blockchain technology can be used to build a credit evaluation system to enhance the effectiveness of monitoring and managing smart grids [35]. Due to the provision of information on credit backgrounds, the electricity produced by green energy can be sold at a relatively high price, making green power providers profitable, and companies will be more motivated to use green renewable energy. Thus, blockchain leads to the development of a virtuous circle. In addition, through the 
establishment of a blockchain-based telecommunication evaluation system for users, massive amounts of information can be automatically recorded, user's credit evaluation can be performed through the consideration of corresponding information, and certain electricity price discounts can be implemented for users with good credit. Certain punishment measures can be implemented for users who engage in bad power consumption behaviors such as stealing electricity.

2.2.5. Incentive and Punishment System. Using the blockchain, one can create a virtual currency to represent each unit of electricity. This system is very useful in the case of renewable energy produced by consumers themselves. In addition, incentive schemes can be implemented to promote renewable energy. By monitoring the transaction history in the blockchain ledger, one can select a group of peers who contributed the most to renewable energy transactions and reward them with virtual currency [36]. Pop et al. [17] proposed a smart grid monitoring system based on blockchain and smart contracts. Smart contracts set rules to identify malicious use points and can detect the malicious manipulation of usage data and enforce penalties. Smart contracts include provisions for decentralized control, the calculation of incentives or penalties, the verification of demand response protocols, and rules related to balancing grid-measured energy demand and energy production [15].

2.2.6. Power Grid Optimization. Amrollahi and Bathaee [37] studied the scale optimization of the microgrid integrating hybrid photovoltaic and wind energy systems and the impact of the demand response on scale optimization. Various model frameworks have been proposed today with the main purpose of reducing the cost of consumers using different pricing incentives [38]. A user's electricity consumption data can be obtained using a smart meter; another function of smart grids is to predict and make recommendations regarding the user's electricity consumption behavior, make full use of the distributed energy generation capacity, and reduce peak electricity use through the migration of system pressure created by electricity use to improve the operating efficiency of power systems [22].

2.2.7. Demand-Side Management. Demand-side management technology matches demand with the availability of resources in a given environment, effectively utilizing existing infrastructure in smart grids. Power demand-side management under blockchain technology is an effective tool that can be used to meet increasing demand [9]. Jabbarzadeh et al. [39] introduced how an interactive system between users and suppliers can be built using a smart grid system, which can effectively improve the poor operability of demand-side management. Smart grids can achieve two-way communication between supply and demand; however, the increased system complexity due to the introduction of demand-side management is a problem that arises when using smart grids. To solve this problem, an automatic control system for energy consumption scheduling based on game theory was developed. This system uses intelligent algorithms instead of manual scheduling, thereby reducing the complexity of the work of the supplier system's staff [38].

\subsection{Environment}

2.3.1. Low Carbon Emission. Based on the use of blockchain technology and information communication technology, energy input and carbon footprint can be reduced [40]. In this process, blockchain can provide a special platform for carbon emission measurement and right certification. Blockchain can be used to register and store emission credits in a distributed database for carbon emission trading to verify renewable energy encryption credits [41]. Saberi et al. [5] proposed a framework in which the blockchain forms the basis for the detection, verification, and reporting processes in carbon trading by providing unalterable and transparent permit records.

2.3.2. Green Energy. Li et al. [21] proposed that the blockchain provides a reliable and transparent means to encourage green energy utilization and reduce energy waste in a flexible and controllable way. Specifically, blockchain can track all transactions in a network so that consumers can know the source of each unit of power and selectively use a certain type of energy, further promoting the use of green energy and reducing environmental pollution [18] (see Table 1).

\section{Method}

ISM and DEMATEL are appropriate techniques for establishing clear hierarchies and relationship structures. Although there are many similarities between the two approaches, ISM divides the relationships among criteria into four categories, which is used to decompose complex systems into subsystems, while DEMATEL uses a more complex assessment. It focuses more on the micro aspect, helps to determine the strength of direct and indirect relationships among criteria, and visualizes causal structures through the use of diagrams [42]. The integration of these two methods can not only obtain the hierarchy of multifactor action in complex systems but also determine the key factors in the hierarchy, which lays a foundation for the analysis and decision-making of complex systems.

Fuzzy mathematics is a way of simulating fuzzy information processing in the human brain $[43,44]$. In addition, the fuzzy concept allows the capture of human bias and uncertainty that DEMATEL cannot handle in the data, so the credibility of analysis results can be improved, and more valuable reference can be provided for managers' decisionmaking. Hence, this study used Fuzzy-DEMATEL for analysis.

\subsection{Calculation Process: Fuzzy-DEMATEL.}

Step 1: taking the research problem as the starting point, the impact factor system is constructed, which is set as $F 1, F 2, \ldots, F n$. 
TABle 1: Aspects and criteria.

\begin{tabular}{|c|c|c|}
\hline Aspects & Criteria & Explanation \\
\hline \multirow{5}{*}{ Economic } & $\begin{array}{l}\text { C1 Public infrastructure } \\
\text { utilization efficiency }\end{array}$ & $\begin{array}{l}\text { Uses blockchain technology to realize the sharing of public infrastructure facilities, } \\
\text { cross-network cooperation, and scattered transactions and improve the sharing } \\
\text { efficiency }\end{array}$ \\
\hline & C2 Production cost management & $\begin{array}{c}\text { Uses blockchain technology to analyze production information to achieve the optimal } \\
\text { production and generation efficiency }\end{array}$ \\
\hline & $\begin{array}{l}\text { C3 Administration cost } \\
\text { management }\end{array}$ & $\begin{array}{c}\text { Reduces labor cost through automatic data upload, traceability system, and smart } \\
\text { contract }\end{array}$ \\
\hline & C4 Transaction & Distributed ledger and smart $\mathrm{c}$ \\
\hline & C5 Financial & Electronic bill management, auditing, \\
\hline \multirow{7}{*}{ Society } & C6 S & Builds a secure dat: \\
\hline & C7 Authenticity & Establishes an open, transparent, authentic, and reliable traceability system \\
\hline & C8 Timeliness & Improves efficiency through the smart contract and blockchain traceability system \\
\hline & C9 Credit evaluation system & Credit evaluation through the integration of information on the blockchain \\
\hline & $\begin{array}{l}\text { C10 Incentive and punishment } \\
\text { system }\end{array}$ & Policy subsidies and illegal punishment for the behavior of blockchain participants \\
\hline & C11 Power grid optimization & $\begin{array}{c}\text { Microgrid regional power supply, optimal power supply, and attract more power } \\
\text { suppliers }\end{array}$ \\
\hline & C12 Demand-side management & $\begin{array}{l}\text { Encourages users to upload demand information to cope with peak hours of power } \\
\text { consumption and match energy production with demand }\end{array}$ \\
\hline \multirow[t]{2}{*}{ Environment } & C13 Low carbon emission & $\begin{array}{c}\text { Carbon emission trading on the chain promotes enterprises to reduce carbon emissions } \\
\text { through technological progress }\end{array}$ \\
\hline & C14 Gre & Replaces nonrenewable energy with green energy \\
\hline
\end{tabular}

Step 2: the relationship among the factors in the system is determined by the expert scoring method. The semantic quantization conversion used by experts is shown in Table 2.

Step 3: use the CFCS method to obtain the $n$-order direct impact matrix:

(a) Normalize the triangular fuzzy number:

$$
\begin{aligned}
& x a_{1 i j}^{k}=\frac{\left(a_{1 i j}^{k}-\min a_{1 i j}^{k}\right)}{\Delta_{\min }^{\max }}, \\
& x a_{2 i j}^{k}=\frac{\left(a_{2 i j}^{k}-\min a_{1 i j}^{k}\right)}{\Delta_{\min }^{\max }}, \\
& x a_{3 i j}^{k}=\frac{\left(a_{3 i j}^{k}-\min a_{1 i j}^{k}\right)}{\Delta_{\min }^{\max }},
\end{aligned}
$$

(b) Normalize the right and left side:

$$
\begin{aligned}
x l s_{i j}^{k} & =\frac{x a_{2 i j}^{k}}{\left(1+x a_{2 i j}^{k}-x a_{1 i j}^{k}\right)}, \\
x r s_{i j}^{k} & =\frac{x a_{3 i j}^{k}}{\left(1+x a_{3 i j}^{k}-x a_{2 i j}^{k}\right)} .
\end{aligned}
$$

(c) Calculate the clarity value of the score:

$$
\begin{aligned}
x_{i j}^{k} & =\frac{\left[x l s_{i j}^{k}\left(1-x l s_{i j}^{k}\right)+x r s_{i j}^{k} x r s_{i j}^{k}\right]}{\left[1-x l s_{i j}^{k}+x r s_{i j}^{k}\right]}, \\
z_{i j}^{k} & =\min a_{1 i j}^{k}+x_{i j}^{k} \times \Delta_{\min }^{\max } .
\end{aligned}
$$

TABLE 2: Semantic transformation.

\begin{tabular}{lc}
\hline Language variable & TFN \\
\hline $\mathrm{N}$ & $(0,0,0.2)$ \\
$\mathrm{VL}$ & $(0,0.2,0.4)$ \\
$\mathrm{L}$ & $(0.2,0.4,0.6)$ \\
$\mathrm{H}$ & $(0.4,0.6,0.8)$ \\
$\mathrm{VH}$ & $(0.8,1,1)$ \\
\hline
\end{tabular}

(d) Calculate the average clarity value:

$$
z_{i j}^{k}=\frac{\left(z_{i j}^{1}+z_{i j}^{2}+\cdots+z_{i j}^{k}\right)}{n} .
$$

Step 4: normalize $Z$.

$$
\lambda=\frac{1}{\max _{1 \leq i \leq n} \sum_{j=1}^{n} z_{i j}}, \quad G=\lambda Z .
$$

Step 5: in line with $T=G+G^{2}+\cdots+G^{n}$ or $T=G(E-G)^{-1}, E$ is the constant matrix, then composite impact matrix $T$ is taken.

Step 6: the degree of influence and being influenced are the values obtained by adding each row and each column of the composite impact matrix:

$$
\begin{aligned}
& D i=\sum_{j=1}^{n} t_{i j} \quad(i=1,2, \ldots, n), \\
& R i=\sum_{i=1}^{n} t_{i j} \quad(i=1,2, \ldots, n) .
\end{aligned}
$$

The formulas of centrality and causality are 


$$
\begin{array}{ll}
m_{i}=D_{i}+R_{i} & (i=1,2, \ldots, n), \\
n_{i}=D_{i}-R_{i} & (i=1,2, \ldots, n), \\
H=T_{i}-R_{i} & (i=1,2, \ldots, n) .
\end{array}
$$

3.2. Calculation Process: ISM. ISM is an intuitive model that can transform fuzzy things into good structural relationships [45].

$$
\begin{aligned}
& H=T+E=h_{i j}, \\
& \lambda=\alpha+\beta .
\end{aligned}
$$

Among them, $\alpha$ and $\beta$ are the mean and standard deviation.

Determine the reachability matrix among factors:

$$
\begin{gathered}
M=\left[m_{i j}\right]_{n * n}, \quad(i=1,2, \ldots, n ; j=1,2, \ldots, n), \\
m_{i j}=\left\{\begin{array}{ll}
1, & h \geq \lambda, \\
0, & h \leq \lambda,
\end{array}(i=1,2, \ldots, n ; j=1,2, \ldots, n),\right. \\
C\left(f_{i}\right)=L\left(f_{i}\right) \cap P\left(f_{i}\right) .
\end{gathered}
$$

According to formula (13), $L\left(f_{i}\right)$ is the reachable set, and $P\left(f_{i}\right)$ is the antecedent set. Ultimately, we can determine the composition of the ISM model.

\section{Result}

We select 7 experts with over 8 years of work experience in power companies to evaluate the research. Individual faceto-face interviews were used for data collection. First of all, the purpose and significance of this research are explained. Secondly, the concept involved in the questionnaire is explained. Then, the questions are answered in the process of expert scoring. Finally, the expert score sheet is recycled. After processing the data, the direct impact matrix is determined; see Table 3 for details.

Normalize the direct influence matrix, and then calculate the comprehensive influence matrix, as shown in Table 4.

From equations (6)-(9), we can get causality, centrality, influence degree, and affected degree, as shown in Table 5. Influence degree indicates the extent to which other indicators are affected. Affected degree indicates the degree of influence by other indicators. Centrality represents the position and the magnitude of its influence. Causality reflects the causal relationship among the influencing criteria.

The DEMATEL causal diagram of the factors is drawn as shown in Figure 1.

There are 6 causal factors, including authenticity (C7), power grid optimization (C11), green energy (C14), timeliness (C8), incentive and punishment system (C10), and security (C6). Among them, security (C6) is the main driver with an influence degree of 2.3556 . There are 8 outcome factors, including administration cost management (C3), financial cost management (C5), production cost management $(\mathrm{C} 2)$, public infrastructure utilization efficiency (C1), demand-side management (C12), transaction cost management (C4), credit evaluation system (C9), and low carbon emission (C13). For centrality, the factors follow the order of security (C6), incentive and punishment system (C10), authenticity (C7), power grid optimization (C11), timeliness (C8), green energy (C14), demand-side management (C12), credit evaluation system (C9), administration cost management (C3), low carbon emission (C13), transaction cost management (C4), public infrastructure utilization efficiency (C1), financial cost management (C5), and production cost management (C2).

The overall influence matrix from equation (10) is shown in Table 6.

Table 7 is the result calculated according to formulas (11) and (12), which supports the stratification in Table 8 and Figure 1. In Table 7, the study introduces $\lambda$ as a threshold to determine whether the two factors have impact.

The first-order decomposition structure is shown in Table 8.

$\mathrm{Nq}$ of each layer is ultimately obtained as follows: $N 1=$ $\{C 2, C 3, C 5\}$, primary node; $N 2=\{C 1, C 4, C 9, C 12, C 13\}$, secondary node; $N 3=\{C 7, C 8, C 11, C 14\}$, third-level node; $N 4=\{C 6$, C10 $\}$, fourth-level node. According to the above analysis, based on the method of ISM, the hierarchical theoretical framework for smart grids under the blockchain technology has been shown in Figure 2.

\section{Discussion}

This paper tries to build the smart grid sustainable supply chain under the blockchain. This research proposes a set of smart grid development standard systems and establishes a hierarchical model.

First, the incentive and punishment system and security are at the first level of ISM and have the highest central position. Therefore, social issues are the core of promoting a whole smart grid under the blockchain. Smart grids under the blockchain are oriented to solve social problems, and they conform to the assumption that technology promotion needs to be constructed from the social problem perspective, which is consistent with social construction theory. It has been pointed out that institutions can play an important role in leading, guiding, and overall planning and then influencing and determining the bottom level. The premise of technological advancement is to take the perfect top-level design of institutions as the supporting basis and solve social problems through making technology more perfect in its application in the society, the economy, and the environment [46]. In the construction of our entire hierarchical model, the incentive and punishment system is part of the top-level system design. Security is still a social issue at the first level, reflecting the fact that the power grid industry is still part of the national security system, which concerns people's livelihood and national defense [13]. This part of the conclusion, regarding security, reflects the characteristics of grids in the smart grid industry and helps us grasp the core characteristics and potential attributes of a national pillar industry. 
TABLE 3: Direct influence matrix of the blockchain on the smart grid.

\begin{tabular}{lccccccccccccccc}
\hline & $\mathrm{C} 1$ & $\mathrm{C} 2$ & $\mathrm{C} 3$ & $\mathrm{C} 4$ & $\mathrm{C} 5$ & $\mathrm{C} 6$ & $\mathrm{C} 7$ & $\mathrm{C} 8$ & $\mathrm{C} 9$ & $\mathrm{C} 10$ & $\mathrm{C} 11$ & C12 & C13 & C14 \\
\hline C1 & 0.0000 & 0.4337 & 0.4337 & 0.1616 & 0.1071 & 0.0935 & 0.1207 & 0.0935 & 0.1207 & 0.1207 & 0.1071 & 0.1071 & 0.1752 & 0.1207 \\
C2 & 0.0255 & 0.0000 & 0.1480 & 0.1071 & 0.1480 & 0.0119 & 0.0799 & 0.1071 & 0.1207 & 0.0119 & 0.1207 & 0.2160 & 0.0119 & 0.0119 \\
C3 & 0.0935 & 0.1752 & 0.0000 & 0.1344 & 0.1344 & 0.0527 & 0.0663 & 0.0391 & 0.1207 & 0.2160 & 0.0119 & 0.1207 & 0.0935 & 0.0799 \\
C4 & 0.1071 & 0.0119 & 0.4337 & 0.0000 & 0.4337 & 0.1888 & 0.1616 & 0.1888 & 0.1888 & 0.2296 & 0.0119 & 0.1207 & 0.0119 & 0.0119 \\
C5 & 0.0119 & 0.1071 & 0.1207 & 0.1071 & 0.0000 & 0.2024 & 0.1344 & 0.1071 & 0.1344 & 0.1071 & 0.0119 & 0.0799 & 0.0119 & 0.1071 \\
C6 & 0.3384 & 0.1616 & 0.1616 & 0.3248 & 0.3520 & 0.0000 & 0.4881 & 0.4609 & 0.3112 & 0.2432 & 0.4881 & 0.2704 & 0.2568 & 0.4065 \\
C7 & 0.1207 & 0.2840 & 0.3112 & 0.4337 & 0.2160 & 0.1071 & 0.0000 & 0.2840 & 0.4337 & 0.1616 & 0.2024 & 0.0119 & 0.1888 & 0.2160 \\
C8 & 0.1616 & 0.1888 & 0.1071 & 0.4609 & 0.2160 & 0.2976 & 0.0391 & 0.0000 & 0.4337 & 0.2024 & 0.2160 & 0.4609 & 0.1752 & 0.1071 \\
C9 & 0.2432 & 0.0663 & 0.4609 & 0.0663 & 0.4337 & 0.2024 & 0.1888 & 0.1071 & 0.0000 & 0.1071 & 0.0663 & 0.1207 & 0.1480 & 0.0391 \\
C10 & 0.1480 & 0.2840 & 0.3112 & 0.2568 & 0.4337 & 0.2840 & 0.4337 & 0.1888 & 0.2296 & 0.0000 & 0.4609 & 0.3384 & 0.2296 & 0.4881 \\
C11 & 0.4881 & 0.2024 & 0.1888 & 0.0935 & 0.2160 & 0.1207 & 0.2024 & 0.2296 & 0.1888 & 0.1207 & 0.0000 & 0.4337 & 0.4337 & 0.1752 \\
C12 & 0.1752 & 0.1344 & 0.4609 & 0.0935 & 0.1071 & 0.1344 & 0.1344 & 0.1344 & 0.1207 & 0.1480 & 0.1888 & 0.0000 & 0.2840 & 0.1888 \\
C13 & 0.1344 & 0.4065 & 0.2024 & 0.1071 & 0.0799 & 0.2024 & 0.1888 & 0.1071 & 0.1344 & 0.1207 & 0.2024 & 0.2160 & 0.0000 & 0.2024 \\
C14 & 0.4337 & 0.2160 & 0.0391 & 0.1207 & 0.1752 & 0.1752 & 0.1752 & 0.1071 & 0.2024 & 0.2840 & 0.2160 & 0.2840 & 0.4609 & 0.0000 \\
\hline
\end{tabular}

TABLE 4: Comprehensive impact matrix of the blockchain on the smart grid.

\begin{tabular}{lcccccccccccccc}
\hline & C1 & C2 & C3 & C4 & C5 & C6 & C7 & C8 & C9 & C10 & C11 & C12 & C13 & C14 \\
\hline C1 & 0.0438 & 0.1459 & 0.1583 & 0.0798 & 0.0790 & 0.0568 & 0.0688 & 0.0584 & 0.0752 & 0.0656 & 0.0625 & 0.0739 & 0.0803 & 0.0634 \\
C2 & 0.0289 & 0.0263 & 0.0690 & 0.0474 & 0.0629 & 0.0234 & 0.0393 & 0.0443 & 0.0534 & 0.0236 & 0.0461 & 0.0744 & 0.0260 & 0.0216 \\
C3 & 0.0489 & 0.0722 & 0.0465 & 0.0597 & 0.0695 & 0.0385 & 0.0458 & 0.0348 & 0.0597 & 0.0740 & 0.0311 & 0.0601 & 0.0494 & 0.0453 \\
C4 & 0.0655 & 0.0511 & 0.1608 & 0.0514 & 0.1566 & 0.0837 & 0.0824 & 0.0827 & 0.0949 & 0.0930 & 0.0439 & 0.0758 & 0.0445 & 0.0449 \\
C5 & 0.0333 & 0.0551 & 0.0691 & 0.0567 & 0.0428 & 0.0718 & 0.0617 & 0.0528 & 0.0659 & 0.0515 & 0.0325 & 0.0515 & 0.0327 & 0.0517 \\
C6 & 0.1758 & 0.1439 & 0.1724 & 0.1723 & 0.1986 & 0.0877 & 0.2003 & 0.1875 & 0.1808 & 0.1389 & 0.1952 & 0.1706 & 0.1582 & 0.1733 \\
C7 & 0.0900 & 0.1291 & 0.1603 & 0.1594 & 0.1338 & 0.0808 & 0.0633 & 0.1177 & 0.1674 & 0.0925 & 0.0986 & 0.0750 & 0.1016 & 0.0986 \\
C8 & 0.1060 & 0.1123 & 0.1291 & 0.1676 & 0.1397 & 0.1269 & 0.0795 & 0.0644 & 0.1702 & 0.1054 & 0.1105 & 0.1781 & 0.1070 & 0.0837 \\
C9 & 0.0975 & 0.0687 & 0.1682 & 0.0638 & 0.1538 & 0.0855 & 0.0883 & 0.0653 & 0.0549 & 0.0664 & 0.0560 & 0.0762 & 0.0767 & 0.0510 \\
C10 & 0.1288 & 0.1619 & 0.1929 & 0.1475 & 0.2070 & 0.1401 & 0.1843 & 0.1234 & 0.1532 & 0.0824 & 0.1840 & 0.1766 & 0.1469 & 0.1868 \\
C11 & 0.1733 & 0.1257 & 0.1407 & 0.0871 & 0.1252 & 0.0842 & 0.1080 & 0.1073 & 0.1145 & 0.0842 & 0.0630 & 0.1696 & 0.1638 & 0.0971 \\
C12 & 0.0906 & 0.0893 & 0.1717 & 0.0713 & 0.0849 & 0.0727 & 0.0792 & 0.0730 & 0.0825 & 0.0785 & 0.0881 & 0.0599 & 0.1151 & 0.0869 \\
C13 & 0.0824 & 0.1468 & 0.1163 & 0.0751 & 0.0807 & 0.0866 & 0.0920 & 0.0699 & 0.0869 & 0.0708 & 0.0931 & 0.1067 & 0.0548 & 0.0894 \\
C14 & 0.1618 & 0.1275 & 0.1055 & 0.0911 & 0.1181 & 0.0957 & 0.1053 & 0.0815 & 0.1158 & 0.1179 & 0.1111 & 0.1368 & 0.1693 & 0.0627 \\
\hline
\end{tabular}

TABLE 5: Comprehensive impact matrix analysis.

\begin{tabular}{lcccc}
\hline Factor & Influence degree & Affected degree & Centrality & Causality \\
\hline C1 & 1.1116 & 1.3267 & 2.4383 & -0.2151 \\
C2 & 0.5867 & 1.4558 & 2.0425 & -0.8691 \\
C3 & 0.7355 & 1.8609 & 2.5964 & -1.1254 \\
C4 & 1.1311 & 1.3300 & 2.4611 & -0.1989 \\
C5 & 0.7292 & 1.6527 & 2.3819 & -0.9235 \\
C6 & 2.3556 & 1.1343 & 3.4899 & 1.2213 \\
C7 & 1.5682 & 1.2981 & 2.8663 & 0.2700 \\
C8 & 1.6803 & 1.1629 & 2.8432 & 0.5175 \\
C9 & 1.1724 & 1.4752 & 2.6476 & -0.3028 \\
C10 & 2.2159 & 1.1448 & 3.3607 & 1.0710 \\
C11 & 1.6436 & 1.2158 & 2.8594 & 0.4279 \\
C12 & 1.2438 & 1.4852 & 2.7290 & -0.2415 \\
C13 & 1.2514 & 1.3265 & 2.5779 & -0.0751 \\
C14 & 1.6001 & 1.1563 & 2.7564 & 0.4438 \\
\hline
\end{tabular}

Second, timeliness, authenticity, and power grid optimization are in the ISM's second level. The first two are characteristics of the blockchain, while power grid optimization reflects the purpose of smart grid development. In the study of the society as a whole, we divide social problems into two aspects. The first is the social welfare created by the

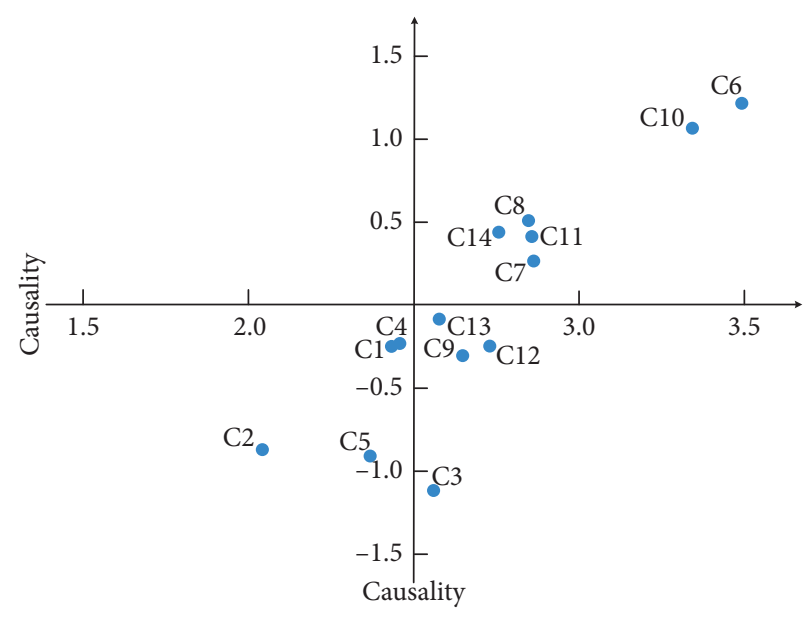

Figure 1: DEMATEL causal diagram.

features of the blockchain. Social welfare is mainly considered from the two aspects of timeliness and authenticity. Every transaction record in the blockchain is bound with the information of the trader so that the transmission path of the transactions between the participants in the smart grid can 
TABLE 6: Overall influence matrix of the blockchain on the smart grid.

\begin{tabular}{lcccccccccccccc}
\hline & $\mathrm{C} 1$ & $\mathrm{C} 2$ & $\mathrm{C} 3$ & $\mathrm{C} 4$ & $\mathrm{C} 5$ & $\mathrm{C} 6$ & $\mathrm{C} 7$ & $\mathrm{C} 8$ & $\mathrm{C} 9$ & $\mathrm{C} 10$ & $\mathrm{C} 11$ & $\mathrm{C} 12$ & $\mathrm{C} 13$ & $\mathrm{C} 14$ \\
\hline C1 & 1.0438 & 0.1459 & 0.1583 & 0.0798 & 0.0790 & 0.0568 & 0.0688 & 0.0584 & 0.0752 & 0.0656 & 0.0625 & 0.0739 & 0.0803 & 0.0634 \\
C2 & 0.0289 & 10.0263 & 0.0690 & 0.0474 & 0.0629 & 0.0234 & 0.0393 & 0.0443 & 0.0534 & 0.0236 & 0.0461 & 0.0744 & 0.0260 & 0.0216 \\
C3 & 0.0489 & 0.0722 & 10.0465 & 0.0597 & 0.0695 & 0.0385 & 0.0458 & 0.0348 & 0.0597 & 0.0740 & 0.0311 & 0.0601 & 0.0494 & 0.0453 \\
C4 & 0.0655 & 0.0511 & 0.1608 & 10.0514 & 0.1566 & 0.0837 & 0.0824 & 0.0827 & 0.0949 & 0.0930 & 0.0439 & 0.0758 & 0.0445 & 0.0449 \\
C5 & 0.0333 & 0.0551 & 0.0691 & 0.0567 & 10.0428 & 0.0718 & 0.0617 & 0.0528 & 0.0659 & 0.0515 & 0.0325 & 0.0515 & 0.0327 & 0.0517 \\
C6 & 0.1758 & 0.1439 & 0.1724 & 0.1723 & 0.1986 & 10.0877 & 0.2003 & 0.1875 & 0.1808 & 0.1389 & 0.1952 & 0.1706 & 0.1582 & 0.1733 \\
C7 & 0.0900 & 0.1291 & 0.1603 & 0.1594 & 0.1338 & 0.0808 & 10.0633 & 0.1177 & 0.1674 & 0.0925 & 0.0986 & 0.0750 & 0.1016 & 0.0986 \\
C8 & 0.1060 & 0.1123 & 0.1291 & 0.1676 & 0.1397 & 0.1269 & 0.0795 & 1.0644 & 0.1702 & 0.1054 & 0.1105 & 0.1781 & 0.1070 & 0.0837 \\
C9 & 0.0975 & 0.0687 & 0.1682 & 0.0638 & 0.1538 & 0.0855 & 0.0883 & 0.0653 & 1.0549 & 0.0664 & 0.0560 & 0.0762 & 0.0767 & 0.0510 \\
C10 & 0.1288 & 0.1619 & 0.1929 & 0.1475 & 0.2070 & 0.1401 & 0.1843 & 0.1234 & 0.1532 & 1.0824 & 0.1840 & 0.1766 & 0.1469 & 0.1868 \\
C11 & 0.1733 & 0.1257 & 0.1407 & 0.0871 & 0.1252 & 0.0842 & 0.1080 & 0.1073 & 0.1145 & 0.0842 & 10.0630 & 0.1696 & 0.1638 & 0.0971 \\
C12 & 0.0906 & 0.0893 & 0.1717 & 0.0713 & 0.0849 & 0.0727 & 0.0792 & 0.0730 & 0.0825 & 0.0785 & 0.0881 & 1.0599 & 0.1151 & 0.0869 \\
C13 & 0.0824 & 0.1468 & 0.1163 & 0.0751 & 0.0807 & 0.0866 & 0.0920 & 0.0699 & 0.0869 & 0.0708 & 0.0931 & 0.1067 & 1.0548 & 0.0894 \\
C14 & 0.1618 & 0.1275 & 0.1055 & 0.0911 & 0.1181 & 0.0957 & 0.1053 & 0.0815 & 0.1158 & 0.1179 & 0.1111 & 0.1368 & 0.1693 & 1.0627 \\
\hline
\end{tabular}

TABLE 7: Reachable matrix of the blockchain on the smart grid.

\begin{tabular}{lccccccccccccccc}
\hline$M$ & C1 & C2 & C3 & C4 & C5 & C6 & C7 & C8 & C9 & C10 & C11 & C12 & C13 & C14 \\
\hline C1 & 1 & 1 & 1 & 0 & 0 & 0 & 0 & 0 & 0 & 0 & 0 & 0 & 0 & 0 \\
C2 & 0 & 1 & 0 & 0 & 0 & 0 & 0 & 0 & 0 & 0 & 0 & 0 & 0 & 0 \\
C3 & 0 & 0 & 1 & 0 & 0 & 0 & 0 & 0 & 0 & 0 & 0 & 0 & 0 & 0 \\
C4 & 0 & 0 & 1 & 1 & 1 & 0 & 0 & 0 & 0 & 0 & 0 & 0 & 0 & 0 \\
C5 & 0 & 0 & 0 & 0 & 1 & 0 & 0 & 0 & 0 & 0 & 0 & 0 & 0 & 0 \\
C6 & 1 & 1 & 1 & 1 & 1 & 1 & 1 & 1 & 1 & 0 & 1 & 1 & 1 \\
C7 & 0 & 0 & 1 & 1 & 0 & 0 & 1 & 0 & 1 & 0 & 0 & 0 & 0 & 0 \\
C8 & 0 & 0 & 0 & 1 & 0 & 0 & 0 & 1 & 1 & 0 & 0 & 1 & 0 \\
C9 & 0 & 0 & 1 & 0 & 1 & 0 & 0 & 0 & 1 & 0 & 0 & 0 & 0 \\
C10 & 0 & 1 & 1 & 1 & 1 & 0 & 1 & 0 & 1 & 1 & 1 & 1 & 1 \\
C11 & 1 & 0 & 0 & 0 & 0 & 0 & 0 & 0 & 0 & 0 & 1 & 1 & 1 \\
C12 & 0 & 0 & 1 & 0 & 0 & 0 & 0 & 0 & 0 & 0 & 0 & 1 & 0 \\
C13 & 0 & 1 & 0 & 0 & 0 & 0 & 0 & 0 & 0 & 0 & 0 & 0 & 0 \\
C14 & 1 & 0 & 0 & 0 & 0 & 0 & 0 & 0 & 0 & 0 & 0 & 0 & 1 \\
\hline
\end{tabular}

TABLe 8: First-order decomposition structure.

\begin{tabular}{|c|c|c|c|}
\hline$I$ & $L\left(f_{i}\right)$ & $P\left(f_{i}\right)$ & $C\left(f_{i}\right)=L\left(f_{i}\right) \cap P\left(f_{i}\right)$ \\
\hline C1 Public infrastructure utilization efficiency & $1,2,3$ & $1,6,11,14$ & 1 \\
\hline $\mathrm{C} 2$ Production cost management & 2 & $1,2,6,10,13$ & 2 \\
\hline C3 Administration cost management & 3 & $1,3,4,6,7,9,10,12$ & 3 \\
\hline C4 Transaction cost management & $3,4,5$ & $4,6,7,8,10$ & 4 \\
\hline C5 Financial cost management & 5 & $4,5,6,9,10$ & 5 \\
\hline C6 Security & $1,2,3,4,5,6,7,8,9,11,12,13,14$ & 6 & 6 \\
\hline C7 Authenticity & $3,4,7,9$ & $6,7,10$ & 7 \\
\hline C8 Timeliness & $4,8,9,12$ & 6,8 & 8 \\
\hline C9 Credit evaluation system & $3,5,9$ & $6,7,8,9,10$ & 9 \\
\hline C10 Incentive and punishment system & $2,3,4,5,7,9,10,11,12,13,14$ & 10 & 10 \\
\hline C11 Power grid optimization & $1,11,12,13$ & $6,10,11$ & 11 \\
\hline C12 Demand-side management & 3,12 & $6,8,10,11,12$ & 12 \\
\hline C13 Low carbon emission & 2,13 & $6,10,11,13,14$ & 13 \\
\hline C14 Green energy & $1,13,14$ & $6,10,14$ & 14 \\
\hline
\end{tabular}

Note. $i$ represents the number of criteria. $L\left(f_{i}\right)$ represents the factors affected by $C_{i} . P\left(f_{i}\right)$ represents the factors that affect $C_{i} . L\left(f_{i}\right) \cap P\left(f_{i}\right)$ represents the intersection.

be fully recorded and traced; this information cannot be destroyed or tampered with, which increases the convenience of the supervision of transactions [27]. The synergy of the blockchain's technical features makes its features perfectly synchronous, eliminates the needless steps involved in the current transaction settlement process [47], and makes the traceability of power products more convenient and efficient. Therefore, mastering the characteristics of the blockchain and understanding the technology and standards of the operation process of the blockchain technology are a 


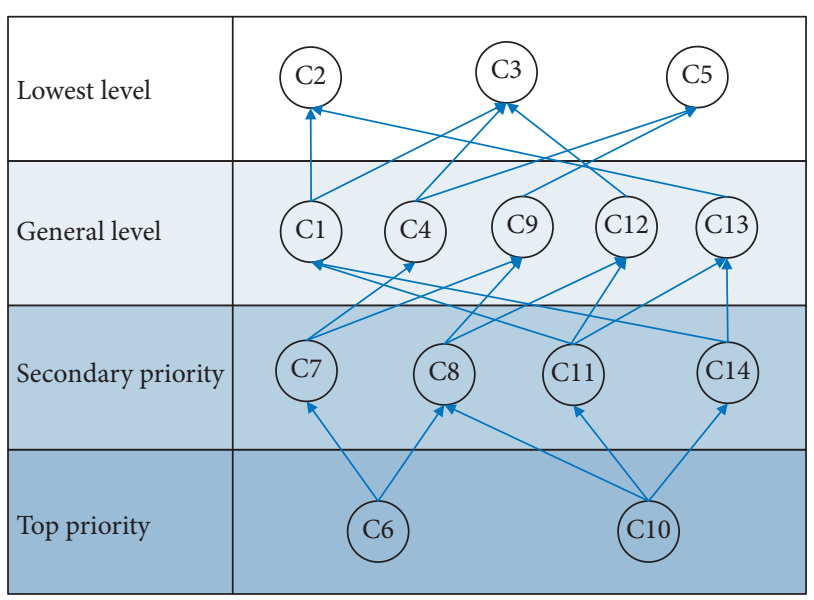

Figure 2: The hierarchical theoretical framework for smart grids under the blockchain technology.

prerequisite for the implementation of smart grids. We would like to emphasize the key problem of power grid optimization in smart grids. The purpose of the development of a whole smart grid is to continuously optimize the grid, which can improve the efficiency of power generation and transmission, reduce the power supply cost, and reduce the network loss rate [22]. Therefore, solving social problems is the foundation. In the whole process, new technology and industry can be combined in a way that will meet certain standards; we should pay attention to system construction, grasp technical standards, and make clear the goal of power grid development.

In the second level of the ISM, we identified a new criterion of green energy, which belongs to the environmental level. The appearance of this new criterion can indicate some new research directions. Generally, in the process of many industries' sustainable development, environmental issues are paid less attention than social and economic issues. However, in this study, green energy is seen as a new bright spot and can be explained by considering the following two aspects. First, the development of renewable energy can take advantage of blockchain technology. Because blockchain storage involves authentic and decentralized transactions, power producers can attract more small participants to engage in power generation, facilitating more private, small power generation transactions [18]. With increasing environmental concerns, power companies tend to switch from traditional generation to renewable energy, and the development of renewable energy and rapid technological innovation have become the driving forces of the grid supply chain network [47]. Blockchain technology provides more power and increases the feasibility of the development of green energy. Green energy is a target product that uses the blockchain to bring market optimization. Second, green renewable energy is a substitute for grid development for nonrenewable energy [21]. The trend is irreversible, and smart grid development is a new strategy for the future. Therefore, research conclusions on green energy highlight the promotion of energy marketization by blockchain technology and the strategic trend of new energy industry development under blockchain technology. Our research plays a leading and guiding role in the development of the blockchain energy industry.

The third level includes the credit evaluation system and the utilization efficiency of the common infrastructure and involves low carbon emission, demand-side management, and transaction cost management. They represent three different levels of economy, society, and environment and are somewhat complicated. However, if we look at the whole third level, we can find that these five indicators are the concrete manifestation of the blockchain in the application process and the key factors of blockchain operation. The whole operation process of blockchain mainly revolves around smart contracts [48]. Smart contracts have the advantages of data irreversibility, security assurance, and full automation. The application of smart contracts to smart grids will simplify various communication processes and improve operating efficiency [14]. However, whether smart contracts can make people more active in participating requires the establishment of a sound credit evaluation system. In addition, transactions involving smart contracts increase the number of stakeholders [5]. In other words, the emergence of smart contracts will increase the common development of physical and virtual markets. In the process of market operation, smart contracts can promote the utilization efficiency of the real economy, which is mainly reflected in the utilization efficiency of public infrastructure in smart grids, while in virtual markets, it is mainly reflected in low carbon emission as a result of virtual trading and demand-side management [49]. The credit evaluation system guarantees the authenticity and visibility of the whole operation. The results of this part reveal that smart grids are enhanced by the blockchain at the operation level and present the application characteristics of smart contracts in the power grid industry.

Financial cost management, production cost management, and administration cost management are at the last level, and all belong to the economic level, which is different from other industries. For example, in the traditional manufacturing industry, economic problems are of greater concern. The construction of a national smart grid industry not only involves social issues such as people's livelihood and national defense but also shows the strength of the new energy strategy, which promotes the application of blockchain technology to social and environmental problems. Blockchain technology can reduce economic costs to a large extent, which will make it easier to control financial costs [30], reduce power generation production costs, and improve power infrastructure utilization efficiency [21].

Finally, due to the above research conclusions and stakeholder theory [50], this paper built a blockchain-based smart grid sustainable GIP application system on the supply chain level, as shown in Figure 3. It includes a government level, information level, and participant level and shows how stakeholders at all stages of the supply chain can collaborate with the blockchain. This system mainly takes the smart grid cloud platform under the blockchain as the core and spreads the information flow among the participants. The information encrypted cannot be decrypted even if it is 


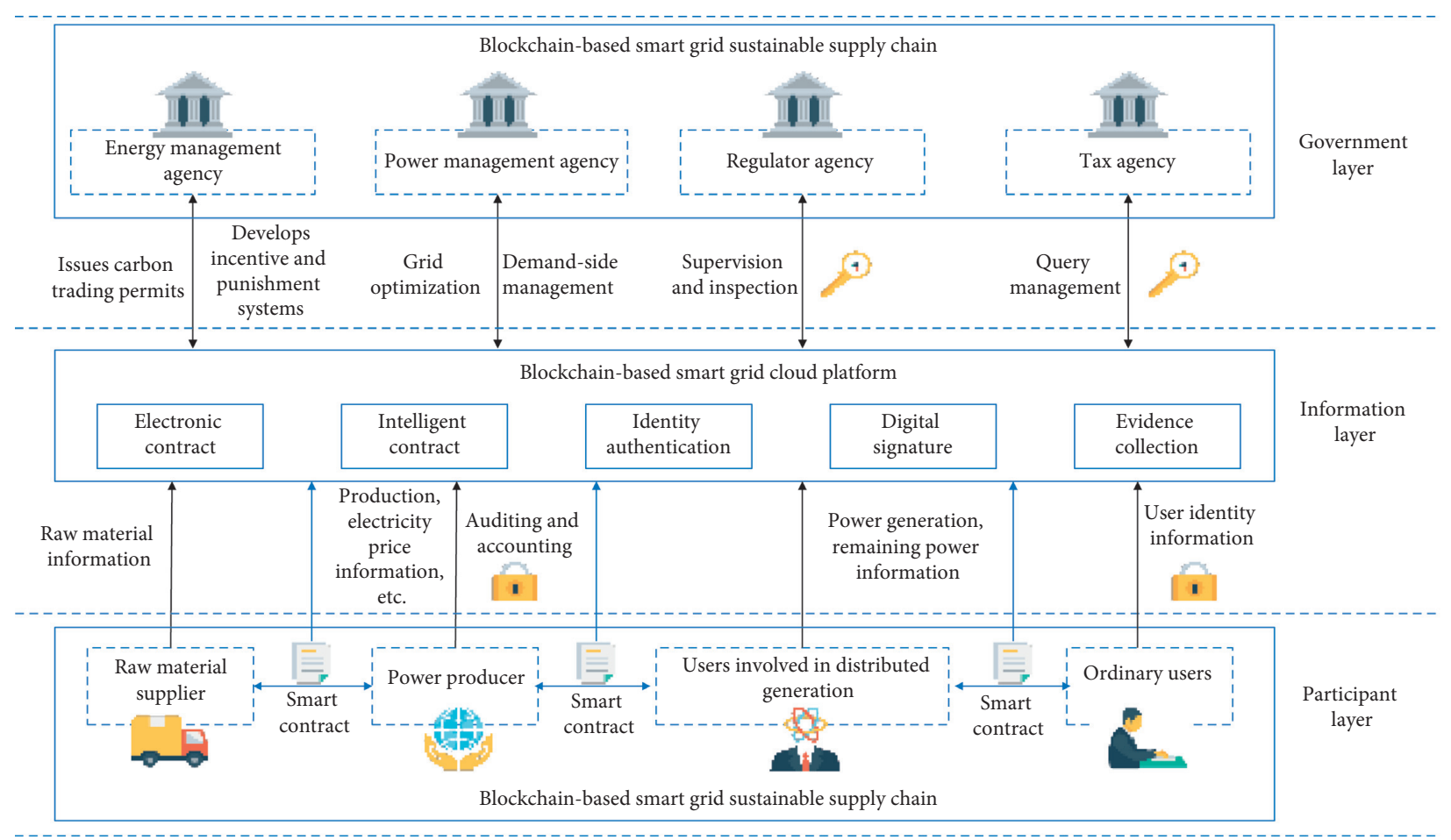

FIgURE 3: A blockchain-based smart grid sustainable GIP application system at the supply chain level.

intercepted on the internet. Blockchain can ensure the stable and efficient operation of the system.

The participation level in the system can be divided into two parts: enterprises and users. Enterprises can be divided into power producers and raw material suppliers. Asymmetric encryption technology enables all transaction information related to the enterprise to be accurately recorded in the blockchain. In addition, enterprises can upload some public information, such as production information, information on the use of raw materials, and electricity prices, to the blockchain to provide data for users' electricity transactions and allow for the supervision of government agencies. At the same time, transactions between participants will automatically generate electronic contracts and upload them to the blockchain cloud platform. Users can be divided into ordinary users and users involved in distributed generation. Ordinary users upload their real identity information that has been encrypted to the blockchain and make transaction requests with virtual identities. Users can inquire about the price of electricity, the source of raw materials for power generation, and so on. Users participating in distributed generation encrypt their real identity information and upload it to the blockchain and, at the same time, upload their power generation information to the public. The blockchain can intelligently match the remaining power generation with the corresponding ordinary users who apply for transactions.

The information level is the core link of the whole GIP application system. Through interactions and data sharing with the management and the participation layer, we can optimize power production, the use of raw materials, trading, and other links in a penetrating manner. In this way, we can realize the whole process of trading, provide customers with dynamic product quality traceability and other services, and enable government agencies to implement management and regulation in a more reasonable and effective way.

The government level is mainly composed of relevant government management agencies. First, an energy management agency can issue carbon emission permits from the blockchain, and enterprises can trade freely. The power agency can integrate information on power grid equipment, power supply and demand, blockchain technology, and other information to make engage in more reasonable power grid planning. Regulators can conduct all-round supervision and inspection of power technology, security, quality, and market prices using keys provided by the blockchain cloud platform. In addition, tax agencies can obtain enterprises' authorization to check the enterprises' accounts, which will lead to more convenient tax management. We expect that this system can promote the sustainable supply chain development of smart grids under the blockchain technology and contribute to the development of the whole national economy.

\section{Conclusion}

The current literature lacks in-depth research on the sustainable supply chain development system covering the whole smart grid value chain under blockchain technology. We analyze the impact of blockchain technology on the sustainable development of smart grids from economic, social, and environmental aspects and construct a hierarchical theory framework. The sustainable GIP application 
system at the supply chain level is systematic and comprehensive, which will help promote the sustainable development of the smart grid industry in the future and provide an important reference for governments and enterprises.

This study also has some limitations. In the process of using Fuzzy-DEMATEL and ISM methods to analyze the 14 influencing factors, this paper only obtains the basic structured results among the influencing factors. Future research also needs to use structural equation modeling and other methods to verify the action path of influencing factors from the operational level.

\section{Data Availability}

Data used to support the findings of this study are available upon request.

\section{Conflicts of Interest}

The authors declare that they have no conflicts of interest.

\section{Acknowledgments}

The authors would like to thank the Yingkou Institute of Technology Excellent Scientific and Technological Talents Foundation (RC201904) and the Dalian University of Technology Fundamental Research Fund (DUT19RW107).

\section{References}

[1] G. Dileep, "A survey on smart grid technologies and applications,” Renewable Energy, vol. 146, pp. 2589-2625, 2020.

[2] D. Appelbaum and S. S. Smith, "Blockchain basics and handson guidance: taking the next step toward implementation and adoption," The CPA Journal, vol. 88, no. 6, pp. 28-37, 2018.

[3] F. Hawlitschek, B. Notheisen, and T. Teubner, "The limits of trust-free systems: a literature review on blockchain technology and trust in the sharing economy," Electronic Commerce Research and Applications, vol. 29, pp. 50-63, 2018.

[4] B. Bhushan, A. Khamparia, K. M. Sagayam, S. K. Sharma, M. A. Ahad, and N. C. Debnath, "Blockchain for smart cities: a review of architectures, integration trends and future research directions," Sustainable Cities and Society, vol. 61, Article ID 102360, 2020.

[5] S. Saberi, M. Kouhizadeh, J. Sarkis, and L. Shen, "Blockchain technology and its relationships to sustainable supply chain management," International Journal of Production Research, vol. 57, no. 7, pp. 2117-2135, 2019.

[6] K. Gai, Y. Wu, L. Zhu, M. Qiu, and M. Shen, "Privacy-preserving energy trading using consortium blockchain in smart grid," IEEE Transactions on Industrial Informatics, vol. 15, no. 6, pp. 35483558, 2019.

[7] H. Zhang, J. Wang, and Y. Ding, "Blockchain-based decentralized and secure keyless signature scheme for smart grid," Energy, vol. 180, pp. 955-967, 2019.

[8] B. P. Hayes, S. Thakur, and J. G. Breslin, "Co-simulation of electricity distribution networks and peer to peer energy trading platforms," International Journal of Electrical Power \& Energy Systems, vol. 115, p. 105419, 2020.

[9] S. Noor, W. Yang, M. Guo, K. H. van Dam, and X. Wang, "Energy Demand Side Management within micro-grid networks enhanced by blockchain," Applied Energy, vol. 228, pp. 1385-1398, 2018.

[10] R. Azzi, R. K. Chamoun, and M. Sokhn, "The power of a blockchain-based supply chain," Computers \& Industrial Engineering, vol. 135, pp. 582-592, 2019.

[11] D. Bumblauskas, A. Mann, B. Dugan, and J. Rittmer, “A blockchain use case in food distribution: do you know where your food has been?" International Journal of Information Management, vol. 52, Article ID 102008, 2020.

[12] V. J. Morkunas, J. Paschen, and E. Boon, "How blockchain technologies impact your business model," Business Horizons, vol. 62, no. 3, pp. 295-306, 2019.

[13] J. Lukić, M. Radenković, M. Despotović-Zrakić, A. Labus, and Z. Bogdanović, "Supply chain intelligence for electricity markets: a smart grid perspective," Information Systems Frontiers, vol. 19, no. 1, pp. 91-107, 2017.

[14] J. Xie, H. Tang, T. Huang et al., "A survey of blockchain technology applied to smart cities: research issues and challenges," IEEE Communications Surveys \& Tutorials, vol. 21, no. 3, pp. 2794-2830, 2019.

[15] J. Gao, K. O. Asamoah, E. B. Sifah et al., "Gridmonitoring: secured sovereign blockchain based monitoring on smart grid," IEEE Access, vol. 6, pp. 9917-9925, 2018.

[16] E. Mengelkamp, B. Notheisen, C. Beer, D. Dauer, and C. Weinhardt, "A blockchain-based smart grid: towards sustainable local energy markets," Computer Science-Research and Development, vol. 33, no. 1-2, pp. 207-214, 2018.

[17] C. Pop, T. Cioara, M. Antal, I. Anghel, I. Salomie, and M. Bertoncini, "Blockchain based decentralized management of demand response programs in smart energy grids," Sensors, vol. 18, no. 1, p. 162, 2018.

[18] F. Imbault, M. Swiatek, R. De Beaufort, and R. Plana, "The green blockchain: managing decentralized energy production and consumption," in Proceedings of the 2017 IEEE International Conference on Environment and Electrical Engineering and 2017 IEEE Industrial and Commercial Power Systems Europe (EEEIC/I¿CPS Europe), pp. 1-5, IEEE, Milan, Italy, June 2017.

[19] A. Wörner, A. Meeuw, L. Ableitner, F. Wortmann, S. Schopfer, and V. Tiefenbeck, "Trading solar energy within the neighborhood: field implementation of a blockchainbased electricity market," Energy Informatics, vol. 2, no. 1, p. 11, 2019.

[20] Z. Dong, F. Luo, and G. Liang, "Blockchain: a secure, decentralized, trusted cyber infrastructure solution for future energy systems," Journal of Modern Power Systems and Clean Energy, vol. 6, no. 5, pp. 958-967, 2018.

[21] Y. Li, R. Rahmani, N. Fouassier, P. Stenlund, and K. Ouyang, "A blockchain-based architecture for stable and trustworthy smart grid," Procedia Computer Science, vol. 155, pp. 410-416, 2019.

[22] P. Samadi, A. H. Mohsenian-Rad, R. Schober, V. W. Wong, and J. Jatskevich, "Optimal real-time pricing algorithm based on utility maximization for smart grid," in Proceedings of the 2010 First IEEE International Conference on Smart Grid Communications, pp. 415-420, IEEE, Gaithersburg, MD, USA, October 2010.

[23] S. Yadav and S. P. Singh, "Blockchain critical success factors for sustainable supply chain," Resources, Conservation and Recycling, vol. 152, p. 104505, 2020.

[24] Z. Zheng, S. Xie, H.-N. Dai et al., "An overview on smart contracts: challenges, advances and platforms," Future Generation Computer Systems, vol. 105, pp. 475-491, 2020. 
[25] R. Beck, J. Stenum Czepluch, N. Lollike, and S. Malone, "Blockchain-the gateway to trust-free cryptographic transactions," Research Papers, vol. 153, 2016.

[26] C. G. Schmidt and S. M. Wagner, "Blockchain and supply chain relations: a transaction cost theory perspective," Journal of Purchasing and Supply Management, vol. 25, no. 4, Article ID 100552, 2019.

[27] N. Kshetri, "Will blockchain emerge as a tool to break the poverty chain in the Global South?" Third World Quarterly, vol. 38, no. 8, pp. 1710-1732, 2017.

[28] S. Mann and H. Wüstemann, "Public governance of information asymmetries-The gap between reality and economic theory," The Journal of Socio-Economics, vol. 39, no. 2, pp. 278-285, 2010.

[29] H. Wang, H. Qin, M. Zhao, X. Wei, H. Shen, and W. Susilo, "Blockchain-based fair payment smart contract for public cloud storage auditing," Information Sciences, vol. 519, pp. 348-362, 2020.

[30] B. Putz, F. Menges, and G. Pernul, "A secure and auditable logging infrastructure based on a permissioned blockchain," Computers \& Security, vol. 87, p. 101602, 2019.

[31] H.-P. Lu and C.-I. Weng, "Smart manufacturing technology, market maturity analysis and technology roadmap in the computer and electronic product manufacturing industry," Technological Forecasting and Social Change, vol. 133, pp. 85-94, 2018.

[32] M. Castro and B. Liskov, "Practical Byzantine fault tolerance and proactive recovery," ACM Transactions on Computer Systems, vol. 20, no. 4, pp. 398-461, 2002.

[33] J. Hou, C. Wang, and S. Luo, "How to improve the competiveness of distributed energy resources in China with blockchain technology," Technological Forecasting and Social Change, vol. 151, p. 119744, 2020.

[34] Z. Li, W. M. Wang, G. Liu, L. Liu, J. He, and G. Q. Huang, "Toward open manufacturing," Industrial Management \& Data Systems, vol. 118, no. 1, pp. 303-320, 2018.

[35] A. Kamilaris, A. Fonts, and F. X. Prenafeta-Boldú, "The rise of blockchain technology in agriculture and food supply chains," Trends in Food Science \& Technology, vol. 91, pp. 640-652, 2019.

[36] T. Alladi, V. Chamola, J. J. P. C. Rodrigues, and S. A. Kozlov, "Blockchain in smart grids: a review on different use cases," Sensors, vol. 19, no. 22, p. 4862, 2019.

[37] M. H. Amrollahi and S. M. T. Bathaee, "Techno-economic optimization of hybrid photovoltaic/wind generation together with energy storage system in a stand-alone micro-grid subjected to demand response," Applied Energy, vol. 202, pp. 66-77, 2017.

[38] A.-H. Mohsenian-Rad, V. W. S. Wong, J. Jatskevich, R. Schober, and A. Leon-Garcia, "Autonomous demand-side management based on game-theoretic energy consumption scheduling for the future smart grid," IEEE Transactions on Smart Grid, vol. 1, no. 3, pp. 320-331, 2010.

[39] A. Jabbarzadeh, B. Fahimnia, and S. Rastegar, "Green and resilient design of electricity supply chain networks: a multiobjective robust optimization approach," IEEE Transactions on Engineering Management, vol. 66, no. 1, pp. 52-72, 2017.

[40] M. A. Mutchek and E. D. Williams, "Design space characterization for meeting cost and carbon reduction goals," Journal of Industrial Ecology, vol. 14, no. 5, pp. 727-739, 2010.

[41] V. Brilliantova and T. W. Thurner, "Blockchain and the future of energy," Technology in Society, vol. 57, pp. 38-45, 2019.

[42] G. Büyüközkan and G. Çifçi, "A novel hybrid MCDM approach based on fuzzy DEMATEL, fuzzy ANP and fuzzy
TOPSIS to evaluate green suppliers," Expert Systems with Applications, vol. 39, no. 3, pp. 3000-3011, 2012.

[43] S. Opricovic and G.-H. Tzeng, "Compromise solution by MCDM methods: a comparative analysis of VIKOR and TOPSIS," European Journal of Operational Research, vol. 156, no. 2, pp. 445-455, 2004.

[44] W.-W. Wu and Y.-T. Lee, "Developing global managers' competencies using the fuzzy DEMATEL method," Expert Systems with Applications, vol. 32, no. 2, pp. 499-507, 2007.

[45] Y. Beikkhakhian, M. Javanmardi, M. Karbasian, and B. Khayambashi, "The application of ISM model in evaluating agile suppliers selection criteria and ranking suppliers using fuzzy TOPSIS-AHP methods," Expert Systems with Applications, vol. 42, no. 15-16, pp. 6224-6236, 2015.

[46] H. Liu and B. Lin, "Incorporating energy rebound effect in technological advancement and green building construction: a case study of China," Energy and Buildings, vol. 129, pp. 150-161, 2016.

[47] Y.-C. Tsao and T.-L. Vu, "Power supply chain network design problem for smart grid considering differential pricing and buy-back policies," Energy Economics, vol. 81, pp. 493-502, 2019.

[48] B. Scott, J. Loonam, and V. Kumar, "Exploring the rise of blockchain technology: towards distributed collaborative organizations," Strategic Change, vol. 26, no. 5, pp. 423-428, 2017.

[49] S. Hall and T. J. Foxon, "Values in the Smart Grid: the coevolving political economy of smart distribution," Energy Policy, vol. 74, pp. 600-609, 2014.

[50] R. Scholz, E. Bartelsman, S. Diefenbach et al., "Unintended side effects of the digital transition: European scientists' messages from a proposition-based expert round table," Sustainability, vol. 10, no. 6, p. 2001, 2018. 